\title{
Sorption and desorption of tetracycline on layered manganese dioxide birnessite
}

\author{
W.-T. Jiang $\cdot$ P.-H. Chang $\cdot$ Y.-S. Wang $\cdot$ \\ Y. Tsai $\cdot$ J.-S. Jean $\cdot$ Z. Li
}

Received: 9 March 2013/Revised: 9 December 2013/Accepted: 12 March 2014/Published online: 9 April 2014

(C) Islamic Azad University (IAU) 2014

\begin{abstract}
Birnessite is one of the most common manganese oxides in the clay-sized fraction $(<2 \mu \mathrm{m})$ of soils and has high cation exchange capacity and larger surface area. Birnessite was previously studied for decomposition of selected antibiotics from water. In this study, the removal of tetracycline (TC) by birnessite from aqueous solution was investigated as a function of initial tetracycline concentration, solution $\mathrm{pH}$, temperature, and equilibrium time. Changes in solid phase after TC adsorption and desorption were characterized by X-ray photoelectron spectroscopy, $\mathrm{X}$-ray diffraction (XRD), and Fourier transform infrared analyses. Desorption of exchangeable cations accompanying TC removal and partial desorption of TC from birnessite by $\mathrm{AlCl}_{3}$ confirmed that cation exchange was responsible for TC removal at low initial concentrations. Both the external and internal surface areas were readily available for TC uptake by birnessite. The intercalated TC formed a horizontal monolayer configuration in the interlayer of birnessite as deduced from XRD analyses.
\end{abstract}

Keywords Adsorption - Birnessite - Intercalation . Swelling $\cdot$ Tetracycline

W.-T. Jiang · P.-H. Chang - Y.-S. Wang · Y. Tsai · J.-S. Jean · Z. $\mathrm{Li}$

Department of Earth Sciences, National Cheng Kung University, Tainan 70101, Taiwan

Z. Li (

Department of Geosciences, University of Wisconsin-Parkside, Kenosha, WI 53144, USA

e-mail: li@uwp.edu

\section{Introduction}

Tetracycline (TC) is a family of antibiotics widely used in human therapy and livestock industry (Sarmah et al. 2006). They are poorly absorbed or metabolized in vivo with a rate of 50-80\% releases in unchanged forms in excreta (Bound and Voulvoulis 2004). In addition, they have relatively long half-life, up to 180 days, depending on environmental conditions (Sarmah et al. 2006). Thus, their extensive use and frequent application of animal manures as plant nutrients and soil amendments resulted in accumulation in soils and aquatic systems. For these reasons, many studies were conducted on their interactions with soils, iron oxides, and other clay minerals over the last 10 years (Figueroa et al. 2004, 2010; Figueroa and Mackay 2005; Gu and Karthikeyan 2005, 2008; Gu et al. 2007; Chang et al. 2009a, b, 2012; Li et al. 2010a, b). Although the removal of TC from water was via adsorption onto many types of the geologic solids, degradation of TC in the presence of manganese oxide was also attributed to one of the major mechanisms of TC removal (Chen and Huang 2011; Chen et al. 2011).

TC has multiple ionizable functional groups, resulting in three acid dissociation constants at 3.3, 7.7, and 9.7, respectively (Kulshrestha et al. 2004). As such, TC exists predominantly as (i) a cation, +00 below $\mathrm{pH} 3.3$, (ii) a zwitterion, +-0 between $\mathrm{pH} 3.3$ and 7.7, (iii) a monovalent anion, +- - between $\mathrm{pH} 7.7$ and 9.7, and (iv) a divalent anion $0--$ above $\mathrm{pH}$ 9.7. Therefore, solution $\mathrm{pH}$ has a significant influence on TC uptake by soils, iron hydroxides, and clay minerals. Under acidic-toneutral conditions, TC adsorption by geologic solids was attributed to cation exchange mechanisms, while relative contribution by surface complexation reactions became more important as the solution $\mathrm{pH}$ increased (Figueroa 
and Mackay 2005; Pils and Laird 2007; Gu and Karthikeyan 2008; Chang et al. 2009a, b; Li et al. 2010a, b). Thus, the cation exchange capacity (CEC) of the solids played a vital role in TC uptake.

Birnessite is a phyllomanganate and is one of the most common manganese oxides in the clay-sized fraction $(<2 \mu \mathrm{m})$ of soils (Golden et al. 1986). The charge of Mn in the octahedral layer varies depending on the environment of formation and, consequently, resulting in different numbers of interlayer cations (Post and Veblen 1990). This resulted in a variable CEC of birnessite. For synthetic sodium birnessite, the reported CEC value was up to $2.40 \mathrm{meq} / \mathrm{g}$ (Golden et al. 1986). Sodium ions in birnessite could be fully exchanged with monovalent ions, while partial exchanges could be achieved with $\mathrm{Ca}$ and $\mathrm{Mg}$ cations (Al-Attar and Dyer 2007).

Due to the presence of variable charges of Mn, birnessite was studied for its potential use as an oxidizing agent to facilitate redox reaction for some of the redoxsensitive species. The oxidation of As(III) by manganese oxide was an important reaction in both the natural cycling of As and the development of remediation technology for lowering As(III) concentration in drinking water (Mohan and Pittman 2007). Recently, studies have been conducted to investigate the birnessite-facilitated destruction of TC or ciprofloxacin (CIP) in aqueous solutions (Zhang and Huang 2005; Rubert and Pedersen 2006; Chen and Huang 2011; Chen et al. 2011). An extensive decomposition of clindamycin and lincomycin in aqueous solution could be achieved using synthetic manganese dioxide $\left(\delta-\mathrm{MnO}_{2}\right)$ (Chen et al. 2010). The transformation of sulfadiazine and sulfonamide antimicrobial sulfamethazine (SMZ) by birnessite-type $\delta-\mathrm{MnO}_{2}$ was also reported (Liu et al. 2009; Gao et al. 2012). Oxidative degradation was attributed to the mechanism of sulfadiazine removal from water, while surface precursor complex formation followed by single-electron transfer was attributed to the formation of SMZ radicals which further underwent transformation by at least two pathways. As birnessite has high CEC values, with its layered structure and swelling properties, it could serve as a host mineral for CIP adsorption, particularly in the interlayer positions (Jiang et al. 2013).

This study was conducted at the National Cheng Kung University in Tainan, Taiwan, to extend the investigation of interactions between cationic drugs and birnessite, to further explore whether the removal of cationic drugs by birnessite was dominated by adsorption or by chemical decomposition under different solution conditions, and to continue evaluating the configurations of intercalated cationic drugs in the interlayer of birnessite.

\section{Materials and methods}

Adsorbent and adsorbate properties

Collected from the third adit of the Wutanshan epithermal gold deposits, Chinkuashih, northern Taiwan, the birnessite forms stepped terraces overflowed with drainage discharged from fractures in a mine tunnel. It occurs as spheroidal aggregates of floral flakes (Fig. 1a), each of which is approximately $20 \mathrm{~nm}$ thick and $1-2 \mu \mathrm{m}$ in diameter (Fig. 1b). X-ray energy-dispersive spectroscopic analysis showed that the mineral is predominantly a manganese oxide with minor $\mathrm{Ca}$ and $\mathrm{Fe}$ and trace amounts of $\mathrm{Mg}, \mathrm{Al}, \mathrm{Si}, \mathrm{S}$, and possibly $\mathrm{Mg}$ and $\mathrm{P}$ (Fig. 1c).

The material was identified to be a disordered birnessite by X-ray diffraction (XRD) and had a structural formula approximated as $(\mathrm{Na}, \mathrm{Mg}, \mathrm{K}, \mathrm{Ca}, \mathrm{Ba})_{0.07} \mathrm{Mn}_{2} \mathrm{O}_{4} \cdot n \mathrm{H}_{2} \mathrm{O}$ based on chemical analysis of the whole sample (Jiang et al. 2013). Its CEC value determined by cation exchange with ammonium was $1.43 \mathrm{mmol}_{\mathrm{c}} / \mathrm{g}$, much lower than a reported CEC value of $2.4 \mathrm{mmol}_{\mathrm{c}} / \mathrm{g}$ for a synthetic birnessite after K saturation (Golden et al. 1986). The external specific surface area (SSA) measured by a BET method was $138 \mathrm{~m}^{2} / \mathrm{g}$, also much lower than a reported SSA of $223 \mathrm{~m}^{2} / \mathrm{g}$ for synthetic birnessite (Fendorf et al. 1994), but higher than $32-100 \mathrm{~m}^{2} / \mathrm{g}$ for a few synthetic birnessite with average oxidation state between 3.67 and 3.99 (Wang et al. 2012). The TC used was in an $\mathrm{HCl}$ form purchased from Calbiochem (Darmstadt, Germany). It has a $\log \mathrm{K}_{\mathrm{ow}}$ value of -2.2 to -1.3 (Collaizzi and Klink 1969; Miller et al. 1977).

\section{TC adsorption on birnessite}

For all experiments, each $50-\mathrm{mL}$ centrifuge tube was filled with $0.5 \mathrm{~g}$ wet weight (corresponding to $0.13 \mathrm{~g}$ dry weight) of birnessite and $10 \mathrm{~mL}$ of TC solution. The mixture was shaken on a horizontal shaker at $27{ }^{\circ} \mathrm{C}$ and $150 \mathrm{rpm}$ for $24 \mathrm{~h}$ for all studies except the kinetic study in which the mixing was done with the following time intervals: 0.25 , $0.5,1.0,2.0,4.0,8.0,16.0,24.0$, and $32.0 \mathrm{~h}$. The initial TC concentration was $2.25 \mathrm{mmol} / \mathrm{L}$ for all experiments except the isotherm study in which the initial concentrations varied from 0 to $2.25 \mathrm{mmol} / \mathrm{L}$. As the TC was in an acidic form, the initial solution $\mathrm{pH}$ was between 2.5 and 3.5 and the final solution $\mathrm{pH}$ after adsorption isotherm study was between 7.2 and 7.7. For the temperature-dependent study, the equilibrium temperature was maintained at 27,37 , and $47^{\circ} \mathrm{C}$, while the initial $\mathrm{TC}$ concentrations were at 0.11 , 0.90 , and $2.25 \mathrm{mmol} / \mathrm{L}$. For the study of $\mathrm{pH}$ effects on TC removal, the solution $\mathrm{pH}$ was adjusted with $1.0 \mathrm{M} \mathrm{HCl}$ or 

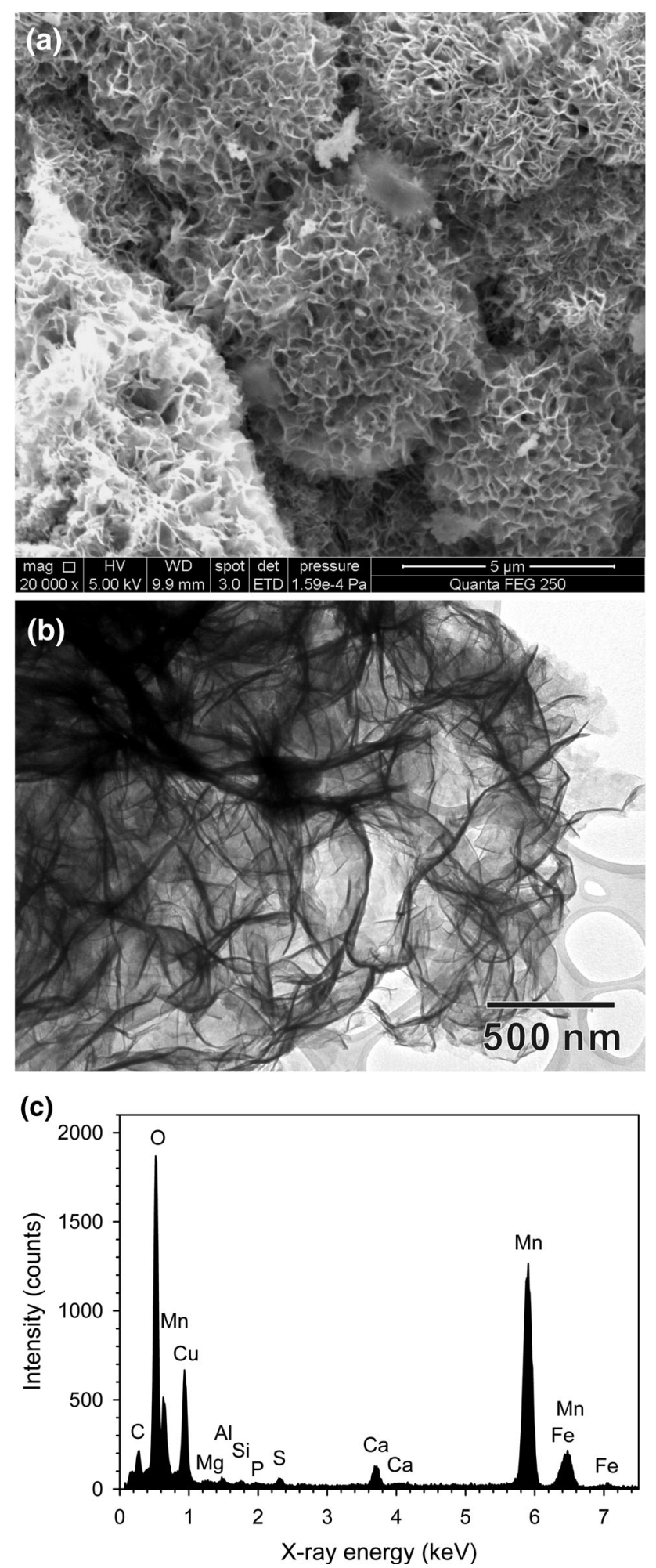

Fig. 1 SEM and TEM microstructures (a and b) and EDS spectrum (c) of the birnessite. The $\mathrm{Cu}$ and $\mathrm{C}$ peaks were from the TEM Cu grid and coated carbon film

$\mathrm{NaOH}$ a few times each with 2-h equilibrium to reach a desired final solution $\mathrm{pH}$ value between 2 and 11 with an increment of 1 .
Tests were performed in duplicates for each experimental variable. After desired time, the mixture was centrifuged for $10 \mathrm{~min}$ at $5,000 \mathrm{rpm}$ and the supernatant passed through $0.45-\mu \mathrm{m}$ syringe filters before being analyzed for equilibrium TC concentration using a UV-Vis method. The amount of TC removed was determined by the difference between the initial and equilibrium TC concentrations.

TC desorption by $\mathrm{AlCl}_{3}$

After the isotherm study for TC removal, the supernatant was removed and $10 \mathrm{~mL}$ of $50 \mathrm{mM} \mathrm{AlCl} \mathrm{Al}_{3}$ solution was added, followed by shaking the mixture for another $24 \mathrm{~h}$. After centrifuge, the supernatant was passed through $0.45-\mu \mathrm{m}$ syringe filters and analyzed for TC concentrations via a UV-Vis method, and then, the amount of TC desorption was calculated. The equilibrium solution $\mathrm{pH}$ was between 3.5 and 3.7.

\section{Methods of analysis}

The equilibrium TC concentrations after filtration were determined via a UV-Vis spectrophotometer (SmartSpec 3000, Bio-Rad Corp.) at the wavelength of $254 \mathrm{~nm}$. The calibration curve was established by six standards in the range of $0-0.122 \mathrm{mmol} / \mathrm{L}$ with the coefficient of regression $r^{2}$ higher than 0.999. The concentrations of $\mathrm{Na}^{+}, \mathrm{K}^{+}$, $\mathrm{Mg}^{2+}$, and $\mathrm{Ca}^{2+}$ cations released from birnessite due to adsorption of TC were measured by an ion chromatograph (Dionex 100) with a mobile phase made of $20 \mathrm{mM}$ methanesulfonic acid. At a flow rate of $1 \mathrm{~mL} / \mathrm{min}$, the retention time for $\mathrm{Na}^{+}, \mathrm{K}^{+}, \mathrm{Mg}^{2+}$, and $\mathrm{Ca}^{2+}$ was $3.8,5.4,8.1$, and $10.1 \mathrm{~min}$, respectively.

For Mn analysis, the supernatant was filtered with $0.45-\mu \mathrm{m}$ syringe filters before being analyzed by a PerkinElmer Optima 7000 DV inductively coupled plasma optical emission spectrometer (ICP-OES). The detection limit was $<1 \mu \mathrm{g} / \mathrm{L}$ with a relative standard deviation $<2 \%$.

The X-ray powder diffraction (XRD) analyses were carried out on a D8 Advance diffractometer (Bruker Corp.) with a $\mathrm{CuK} \alpha$ radiation at $40 \mathrm{kV}$ and $40 \mathrm{~mA}$. Oriented samples were scanned from $3^{\circ}$ to $40^{\circ} 2 \theta$ with a scan speed of $0.01 \%$ sec.

An FEI Quanta 250 FEG scanning electron microscope (SEM) operated at an accelerating voltage of $5 \mathrm{kV}$ and an FEI Tecnai G2 transmission electron microscope (TEM) at $200 \mathrm{kV}$ were used for microstructure and diffraction studies. Both SEM and TEM were equipped with X-ray energy-dispersive spectroscopy (EDS) for qualitative elemental analyses. The birnessite specimen was dispersed in deionized water with an ultrasonic cleaner for a few seconds, and a 300-mesh copper grid with lacey formvar film 


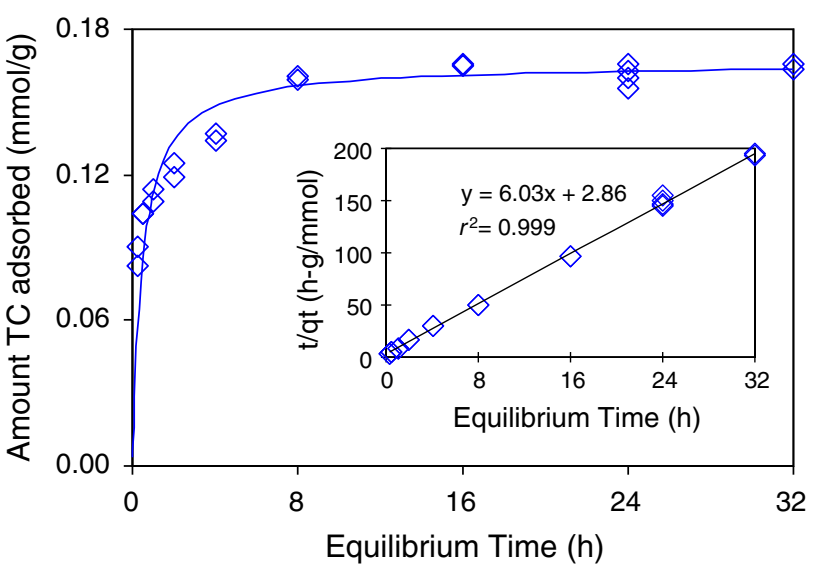

Fig. 2 Adsorption kinetics of TC on birnessite. The solid line is the pseudo-second-order fit to the observed data

coated with carbon was used to collect suspended particles for TEM work.

The FTIR spectra were acquired on a JASCO FT/IR4100 spectrometer equipped with a $\mathrm{ZnSe}$-attenuated total reflection accessory. The spectra were obtained from 650 to $4,000 \mathrm{~cm}^{-1}$ by accumulating 256 scans at a resolution $4 \mathrm{~cm}^{-1}$.

The X-ray photoelectron spectra (XPS) were collected by a PHI 5000 VersaProbe using a monochromatic $\mathrm{Al} \mathrm{K \alpha}$ $\mathrm{X}$-ray $(1,486 \mathrm{eV})$ source at $25 \mathrm{~W}$ and a base pressure of $10^{-8}$ torr in the measuring chamber. Survey scans were performed from 0 to $1,400 \mathrm{eV}$ with a dwell time of $50 \mathrm{~ms}$, a pass energy of $117.4 \mathrm{eV}$, and an energy interval of $1.0 \mathrm{eV}$. Measuring scans were run at a pass energy of $23.5 \mathrm{eV}$ and an energy interval of $0.2 \mathrm{eV}$. Calibration of spectra was made with reference to the $\mathrm{C}$ s1 binding energy at $284.6 \mathrm{eV}$. Spectra were analyzed using the XPSPEAK software (version 4.1 for WIN95/98), and peak fitting of photolines was performed with a Voigt (Gaussian-Lorentzian $=78: 22$ ) function.

\section{Results and discussion}

Kinetics of TC removal by birnessite

The removal of TC by birnessite was fitted to several kinetic models, including zeroth-, first-, and pseudo-second-order kinetics. The pseudo-second-order kinetics provided the best fit with an $r^{2}=0.999$, an initial rate of $0.35 \mathrm{mmol} / \mathrm{g}-\mathrm{h}$, a rate constant of $12.7 \mathrm{~g} / \mathrm{mmol}-\mathrm{h}$, and an equilibrium adsorption value of $0.17 \mathrm{mmol} / \mathrm{g}$ (Fig. 2). These values were of about the same magnitude as the initial rate of $0.32 \mathrm{mmol} / \mathrm{g}-\mathrm{h}$, the rate constant of $6.4 \mathrm{~g} / \mathrm{mmol}-\mathrm{h}$, and the equilibrium adsorption value of
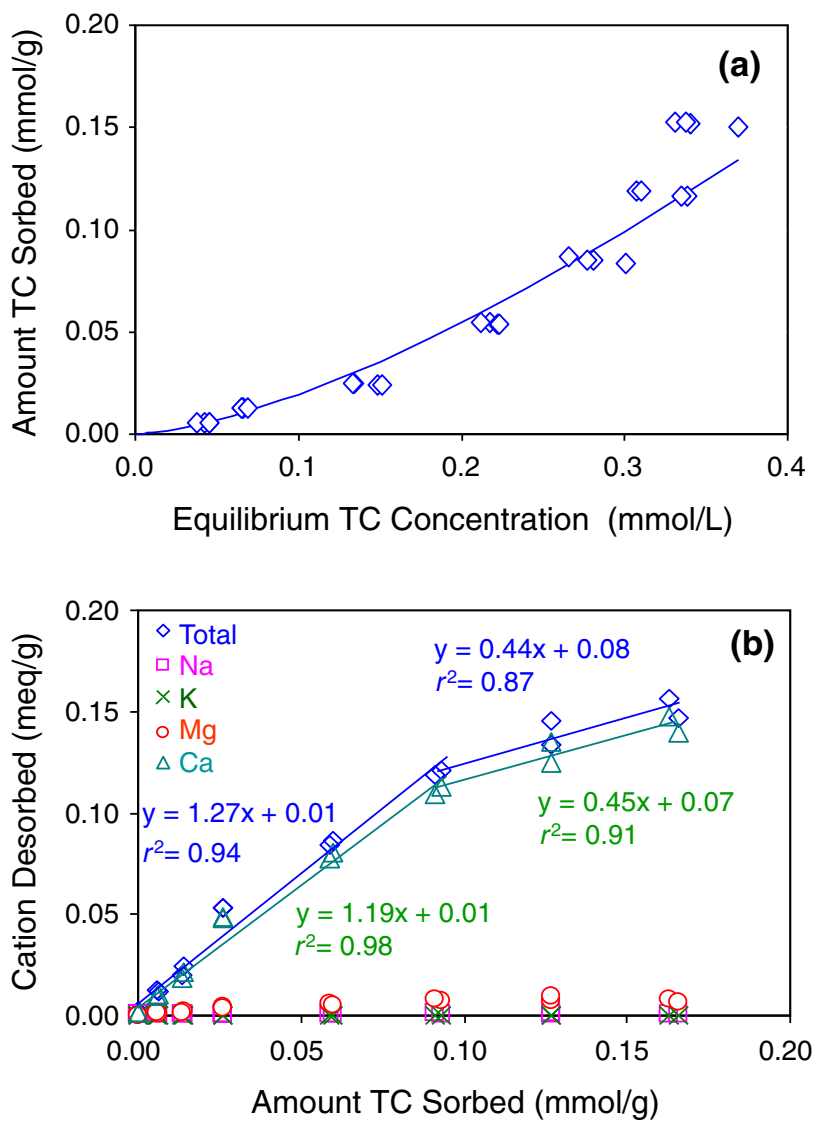

Fig. 3 Adsorption isotherm of TC on birnessite (a). The solid line is the Freundlich fit to the observed data. And desorption of exchangeable cations accompanying TC adsorption on birnessite (b)

$0.22 \mathrm{mmol} / \mathrm{g}$ for CIP adsorption on the same mineral (Jiang et al. 2013). However, the initial rate was much lower than 1.3 and $3.8 \mathrm{mmol} / \mathrm{g}-\mathrm{h}$, and the equilibrium adsorption value was also lower than $0.44 \mathrm{mmol} / \mathrm{g}$ for TC adsorption on swelling clay minerals $\mathrm{Na}-$ and $\mathrm{Ca}$-montmorillonite ( $\mathrm{Li}$ et al. 2010a).

Equilibrium of TC removal by birnessite

The removal of TC by birnessite followed an S-shaped isotherm (Fig. 3a). Several adsorption models were used to fit the experimental data. The shape of the isotherm was better fitted to the Freundlich isotherm instead of the Langmuir isotherm, as the latter resulted in a negative adsorption capacity and a negative adsorption coefficient. The Freundlich isotherm has the form:

$C_{\mathrm{S}}=K_{\mathrm{F}} C_{\mathrm{L}}^{n}$

where the $C_{\mathrm{S}}$ and $C_{\mathrm{L}}$ are solute concentrations in solid and solution phases, $K_{\mathrm{F}}$ is the Freundlich sorption constant, and $n$ is the Freundlich index reflecting the affinity of the solute for the solid phase. An $n<1$ suggests an unfavorable 
sorption, $n=1$ a linear sorption, and $n>1$ a favorable sorption. The fitted parameters were $r^{2}=0.97, K_{\mathrm{F}}=0.58$ $\mathrm{L} / \mathrm{g}$, and $n=1.47$. However, under the given experimental conditions, the TC removal capacity could not be determined from this type of isotherm. The results from this study are totally different from those of TC removal by swelling clays and kaolinite ( $\mathrm{Li}$ et al. 2010a, b) and CIP removal by the same birnessite (Jiang et al. 2013).

A linear regression between the quantities of exchangeable cations released and the amounts of TC adsorbed could not be achieved as the data were somehow curvy (Fig. 3b). However, fitting the data to two segments of straight lines resulted in better fits. The slope was $1.2-1.3$ for the first segment and only $0.44-0.45$ for the second segment. The result suggests that cation exchange was mainly responsible for the removal of TC from solution by birnessite at lower concentrations, while other mechanisms may be corporative at higher TC concentrations. The mechanism other than cation exchange for TC removal by birnessite may account for the enhanced TC sorption at higher equilibrium concentrations as also indicated by the $\mathrm{S}$-shaped isotherm in Fig. 3a. The major exchangeable cation was $\mathrm{Ca}^{2+}$. The equilibrium solution $\mathrm{pH}$ was between 7.2 and 7.7, under which the zwitterionic form $\mathrm{TC}^{ \pm}$is the dominant species in solution. The quantitative exchange between TC adsorbed and exchangeable cations released suggested that the zwitterionic form of TC may still contribute significantly to cation exchange as observed in CIP adsorption by birnessite (Jiang et al. 2013).

Influence of temperature on TC removal by birnessite

Overall, as the temperature of the solution increased, the partitioning coefficient $K_{\mathrm{d}}$, defined as the ratio of the amount of TC sorbed to the equilibrium TC concentration, decreased (Fig. 4). The relationship between $K_{\mathrm{d}}$ and the thermodynamic parameters of sorption is expressed as follows:

$\ln K_{\mathrm{d}}=-\frac{\Delta H}{\mathrm{RT}}+\frac{\Delta S}{R}$

where $\Delta H$ is the change in enthalpy, $\Delta S$ is the change in entropy, $R$ is the gas constant, and $T$ is the adsorption temperature in $K$. The free energy of sorption can be determined by

$\Delta G=\Delta H-T \Delta S$

The calculated thermodynamic parameters are listed in Table 1 . The negative $\Delta G$ values indicate attractive interaction between TC and birnessite surfaces, and the magnitude of $\Delta G$ values suggested physical sorption such as cation exchange. These values are larger than $-8 \mathrm{~kJ} / \mathrm{mol}$
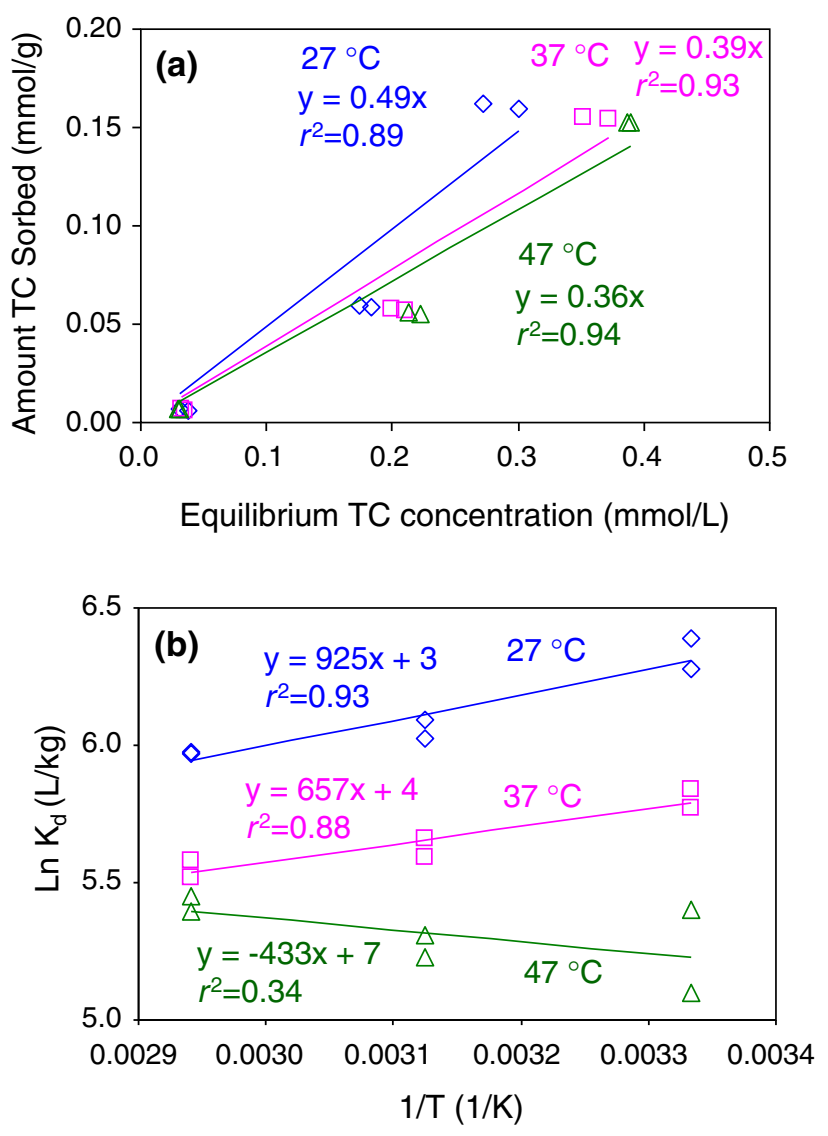

Fig. 4 Influence of temperature on TC sorption on birnessite. The lines are fitted to the observed data based on linear fit (a) and Eq. (2) (b)

Table 1 Thermodynamic values of TC sorption on birnessite at different initial concentrations

\begin{tabular}{lccccc}
\hline $\begin{array}{l}\text { Initial TC } \\
\text { concentration } \\
(\text { mmol/L) }\end{array}$ & \multicolumn{2}{l}{$\Delta G^{\circ}(\mathrm{kJ} / \mathrm{mol})$} & $\begin{array}{l}\Delta H^{\circ}(\mathrm{kJ} / \\
\mathrm{mol})\end{array}$ & $\begin{array}{l}\Delta S^{\circ}(\mathrm{J} / \\
\mathrm{mol}-\mathrm{K})\end{array}$ \\
\cline { 2 - 5 } 0.11 & $300 \mathrm{~K}$ & $310 \mathrm{~K}$ & $320 \mathrm{~K}$ & & \\
\hline 0.90 & -13.0 & -13.6 & -14.2 & 3.6 & 55 \\
2.25 & -14.4 & -14.7 & -15.0 & -5.5 & 30 \\
\hline
\end{tabular}

for TC sorption on silica (Turku et al. 2007), but slightly smaller than TC sorption on palygorskite (Chang et al. 2009b). The small positive $\Delta S$ values indicate that the sorption of TC on birnessite is spontaneous due to an increase in system randomness.

Influence of solution $\mathrm{pH}$ on $\mathrm{TC}$ removal by birnessite

A slight decrease in TC removal was found as the solution $\mathrm{pH}$ increased from 2 to 7.7, the $\mathrm{pK}_{\mathrm{a} 2}$ value of $\mathrm{TC}$, beyond which further increasing in solution $\mathrm{pH}$ to 11 resulted in a significant decrease in TC removal (Fig. 5a). A similar 

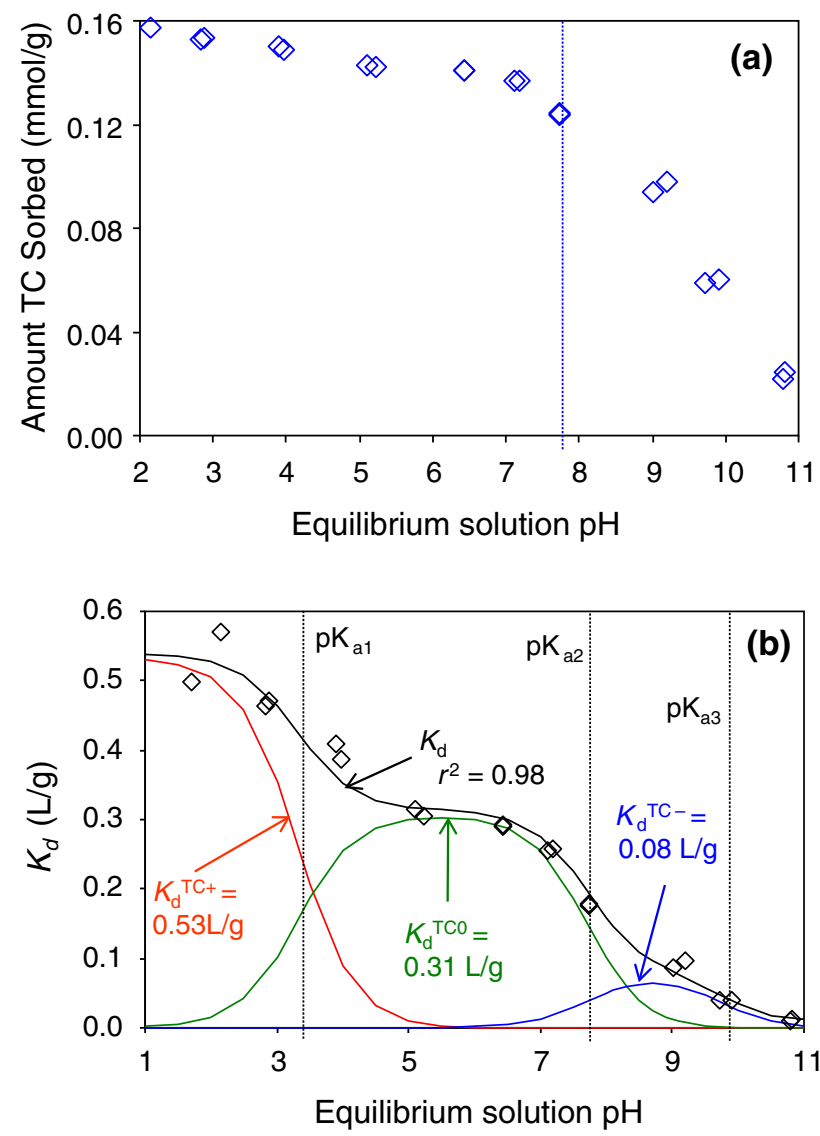

Fig. 5 Sorption TC on birnessite as affected by solution $\mathrm{pH}$ (a) and distribution coefficient of different TC species (b)

trend was found for CIP removal by the same birnessite (Jiang et al. 2013), for TC removal by kaolinite ( $\mathrm{Li}$ et al. 2010b), and for TC removal by illite (Chang et al. 2012). The results again suggested that TC adsorption could be in the species of $\mathrm{TC}^{+}$and $\mathrm{TC}^{ \pm}$, and significant reduction in TC removal was found when it was in an anionic form $\mathrm{TC}^{-}$.

Contributions of different species to the overall TC distribution coefficient $K_{\mathrm{d}}(\mathrm{L} / \mathrm{g})$ can be related to the mass fraction $(\alpha)$ and distribution coefficient of each species by Figueroa et al. 2004:

$K_{\mathrm{d}}=K_{\mathrm{d}}^{\mathrm{TC}+} \alpha^{+}+K_{\mathrm{d}}^{\mathrm{TC} 0} \alpha^{0}+K_{\mathrm{d}}^{\mathrm{TC}-} \alpha^{-}+K_{\mathrm{d}}^{\mathrm{TC} 2-} \alpha^{2-}$

where the superscripts $\mathrm{TC}+, \mathrm{TC} 0, \mathrm{TC}-$, and $\mathrm{TC} 2-$ refer to cationic, zwitterionic, monovalent anionic, and divalent anionic forms of TC, respectively. The $\alpha$ values could be determined for given $\mathrm{pK}_{\mathrm{a}}$ and solution $\mathrm{pH}$ values. Multivariable regression of $\alpha^{+}, \alpha^{0}, \alpha^{-}, \alpha^{2-}$ against $K_{\mathrm{d}}$ under different $\mathrm{pH}$ conditions resulted in $K_{\mathrm{d}}^{\mathrm{TC}+}=0.53 \mathrm{~L} / \mathrm{g}$, $K_{\mathrm{d}}^{\mathrm{TC} 0}=0.31 \mathrm{~L} / \mathrm{g}, K_{\mathrm{d}}^{\mathrm{TC}-}=0.08 \mathrm{~L} / \mathrm{g}$, and $K_{\mathrm{d}}^{\mathrm{TC} 2-}=0.00$ $\mathrm{L} / \mathrm{g}$ with an intercept of 0.01 and $r^{2}$ of 0.98 (Fig. 5b). The results confirmed that the major uptake of TC by birnessite was in cationic and zwitterionic forms.

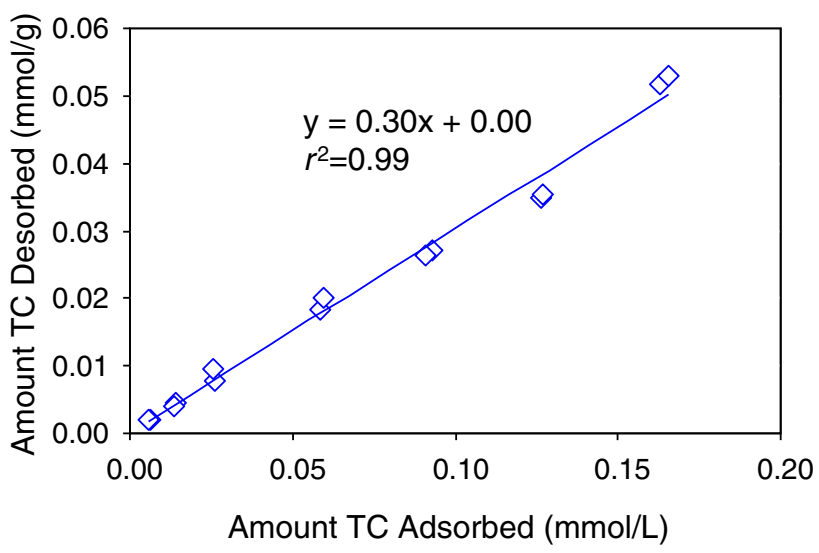

Fig. 6 Desorption of TC from birnessite by $50 \mathrm{mM}$ of $\mathrm{AlCl}_{3}$

Desorption of adsorbed TC using $\mathrm{AlCl}_{3}$

Under the initial $\mathrm{AlCl}_{3}$ concentration of $50 \mathrm{mM}$, the amount of TC desorption increased as the initial TC loading on birnessite increased (Fig. 6). Birnessite could have an $\mathrm{Al}$ sorption capacity of $5 \mu \mathrm{mol} / \mathrm{m}^{2}$, equivalent to $1.1 \mathrm{mmol} / \mathrm{g}$, using the SSA of $223 \mathrm{~m}^{2} / \mathrm{g}$ (Fendorf et al. 1994), or $0.68 \mathrm{mmol} / \mathrm{g}$, using the SSA of $138 \mathrm{~m}^{2} / \mathrm{g}$ in this study. The input $\mathrm{Al}$ for TC desorption was about $4 \mathrm{mmol} / \mathrm{g}$, while the TC adsorption capacity was only $0.22 \mathrm{mmol} / \mathrm{g}$. Thus, the input $\mathrm{AlCl}_{3}$ was sufficient enough to remove all adsorbed TC. Moreover, $\mathrm{Al}^{3+}$ has more replacing power in the Hofmeister lyotropic series. Still, the amount of TC removed accounted for only $1 / 3$ of the initial TC adsorption (Fig. 6), suggesting that the TC adsorbed on birnessite would be either resistant to desorption or be decomposed already after 24-h shaking during the initial adsorption experiment.

\section{XRD analyses}

For raw birnessite, the d-spacings were $\sim 7.5,3.60$, and $2.45 \AA$ (Fig. 7), corresponding to the 001 and 002 reflections and the 20, 11 band of a birnessite with turbostratic disorder (Drits et al. 2007; Grangeon et al. 2010). With an increase in TC loading, a small peak at the low-angle side with a d-spacing of $\sim 9.8 \AA$ started to show up. As the TC adsorption level reached $0.015 \mathrm{mmol} / \mathrm{g}$, the peak height was about the same for both peaks. Further increasing TC loading, the birnessite 001 reflection started to disappear and a less symmetric new peak started to appear (Fig. 7). For a typical dehydrated birnessite, the d-spacing is about $5.5 \AA$ (Renuka and Ramamurthy 2000). The difference between the d-spacings of TC-intercalated and TC-dehydrated birnessite is about $4.3 \AA$. Generally accepted conformations for TC were extended and twisted forms, with the former primarily existing in basic solution when the 


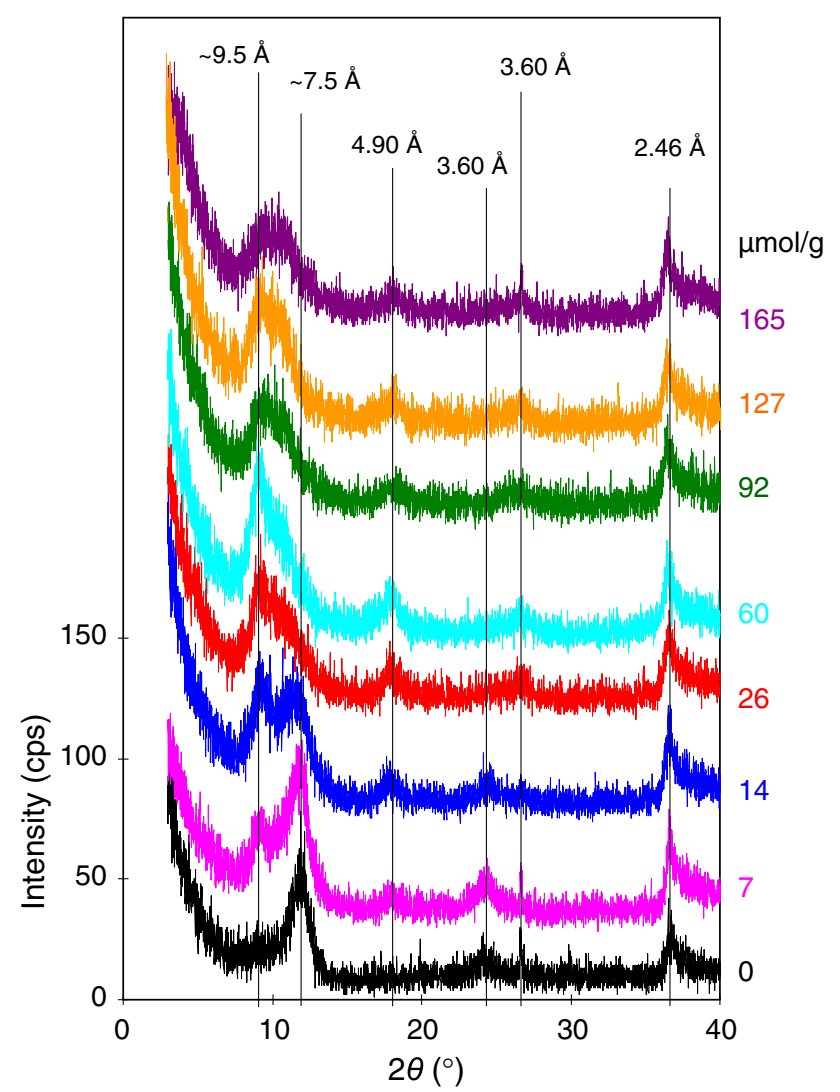

Fig. 7 XRD of birnessite adsorbed with different amounts of TC

dimethylamino group lies below the plane spanned by the ring system (Wessels et al. 1998), while the latter was present in acidic-to-neutral solutions when the dimethylamino group lies above the ring system (Wessels et al. 1998; Duarte et al. 1999; Othersen et al. 2003). In the twisted form, TC was $12.9 \AA$ long, $7.5 \AA$ wide, and $6.2 \AA$ high, occupying an area of $97 \AA^{2}$ when the ring was parallel to the surface (Gambinossi et al. 2004). Swelling and interlayer expansion of birnessite were observed when different types of organic molecules were intercalated into the interlayer spaces. For example, an increase in d-spacing to $32 \AA$ was observed with an intercalation of decylamine into H-birnessite (Ammundsen et al. 1998). Intercalation of tetramethylammonium resulted in an expansion of d-spacing from 7.3 to $15.6 \AA$ (Liu et al. 2000). In this study, the intercalation of TC into the birnessite interlayer could only be achieved partially, which may account for the much lower TC uptake in comparison with the CEC of the mineral. In contrast, intercalation of TC into swelling clay mineral montmorillonite resulted in $\mathrm{d}$-spacing expansion to $22 \AA$ ( $\mathrm{Li}$ et al. 2010a).

The d-spacing decreased back from $\sim 9.8$ to $\sim 7.5 \AA$ after desorption with $50 \mathrm{mM} \mathrm{AlCl}$, regardless of the initial TC loading levels (Fig. 8). The similarity among these

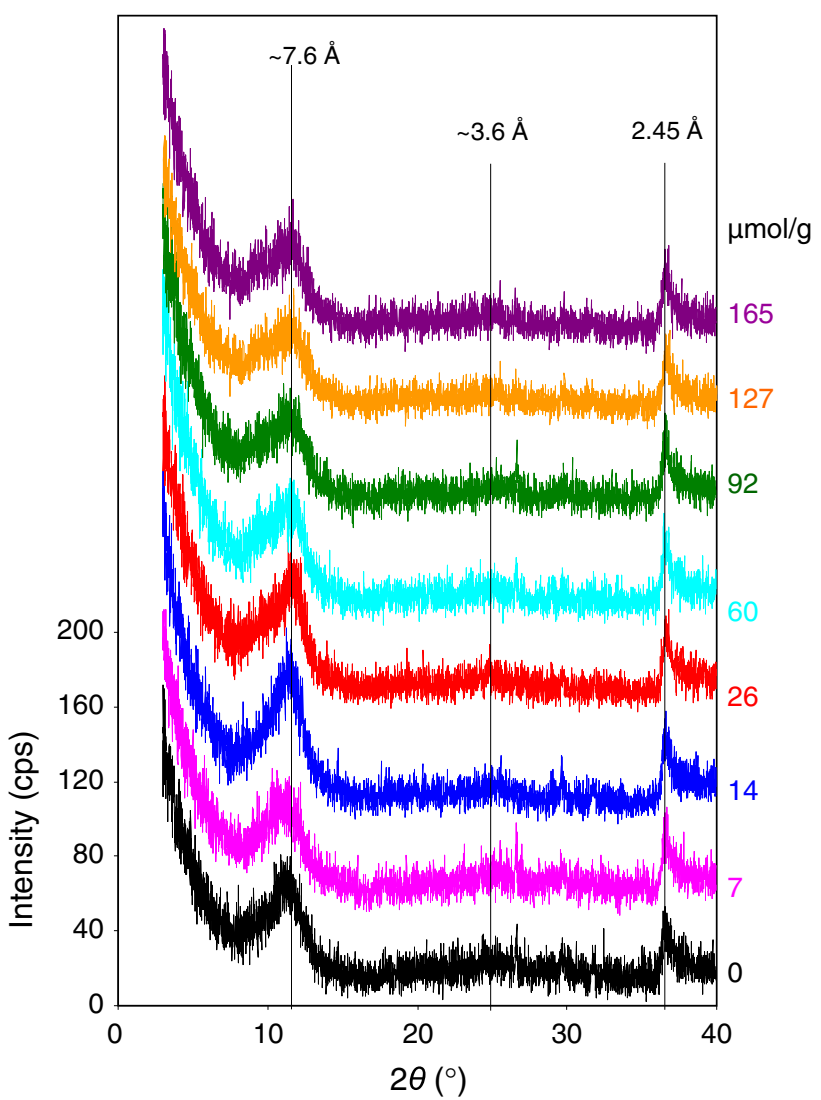

Fig. 8 XRD of birnessite after adsorbed with different amounts of $\mathrm{TC}$ and then desorbed with $50 \mathrm{mM}$ of $\mathrm{AlCl}_{3}$

diffraction patterns suggests that the change in d-spacing was due to substitution of $\mathrm{Al}$ for $\mathrm{TC}$ and intercalation of $\mathrm{Al}$ into the interlayer space. As the initial $\mathrm{Al}$ input was $4 \mathrm{mmol} / \mathrm{g}$, while the $\mathrm{Al}$ adsorption capacity on birnessite was $1.1 \mathrm{mmol} / \mathrm{g}$ (Fendorf et al. 1994), a complete saturation of $\mathrm{Al}$ in the interlayer could be achieved, resulting in an almost identical d-spacing for birnessite after $\mathrm{Al}^{3+}$ desorption.

\section{FTIR analyses}

For raw birnessite, a broad weak peak and a broad strong peak were located at 1,624 and $3,431 \mathrm{~cm}^{-1}$ with the former assigned to less ordered water and the latter to $-\mathrm{OH}, \mathrm{H}_{2} \mathrm{O}$ adsorbed on birnessite (Jokic et al. 2001). Separately, the broad band at $3,280-3,400 \mathrm{~cm}^{-1}$ was assigned to the stretching mode of $\mathrm{OH}$ groups, while the band at $1,610 \mathrm{~cm}^{-1}$ was assigned to the bending mode of $\mathrm{H}_{2} \mathrm{O}$ (White et al. 2009). These bands were present for the samples adsorbed with different amounts of TC, but the band at $3,431 \mathrm{~cm}^{-1}$ shifted to a higher wave number, while the band located at $1,624 \mathrm{~cm}^{-1}$ shifted to a slightly lower wave number with the intercalation of TC (Fig. 9). 


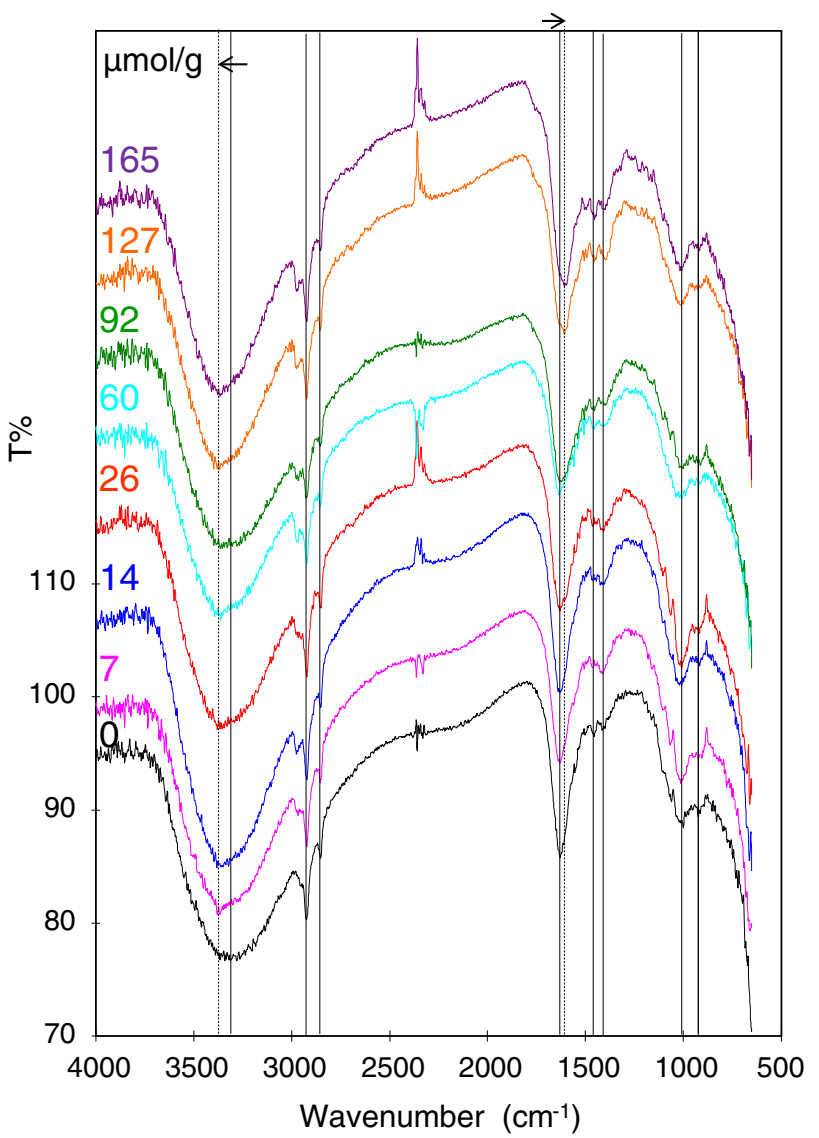

Fig. 9 FTIR spectra of birnessite after adsorbed with different amounts of TC. The solids lines are vibrations of birnessite, and dashed lines are new band locations after shifting

After desorption by $\mathrm{Al}^{3+}$, these two bands retuned to their original wave numbers (Fig. 10). In addition, a broad band occurred at $1,080 \mathrm{~cm}^{-1}$ for all samples after in contact with $50 \mathrm{mM}$ of $\mathrm{AlCl}_{3}$ (Fig. 10). Thus, this broad band should be originated from $\mathrm{Al}$ intercalated in birnessite. Furthermore, the FTIR spectra of birnessite after desorption with $50 \mathrm{mM}$ of $\mathrm{AlCl}_{3}$ were identical, again suggesting a complete exchange of cations and $\mathrm{TC}$ by $\mathrm{Al}^{3+}$.

A band at $1,425 \mathrm{~cm}^{-1}$ was attributed to carbonate (White et al. 2009), which was absent in this study, suggesting that the natural birnessite did not contain carbonate. Thus, the increase in $\mathrm{Ca}^{2+}$ concentration as the amount of TC adsorption increased should not be attributed to dissolution of any carbonate precipitates in the sample.

Sorption mechanism and limiting factor

Previous results of CIP adsorption on birnessite indicated that the specific surface area, rather than the charge density, was the limiting factor for CIP uptake by birnessite (Jiang et al. 2013). The maximum TC adsorption in this study was less than $0.25 \mathrm{mmol} / \mathrm{g}$, in comparison with the $\mathrm{CEC}$ of

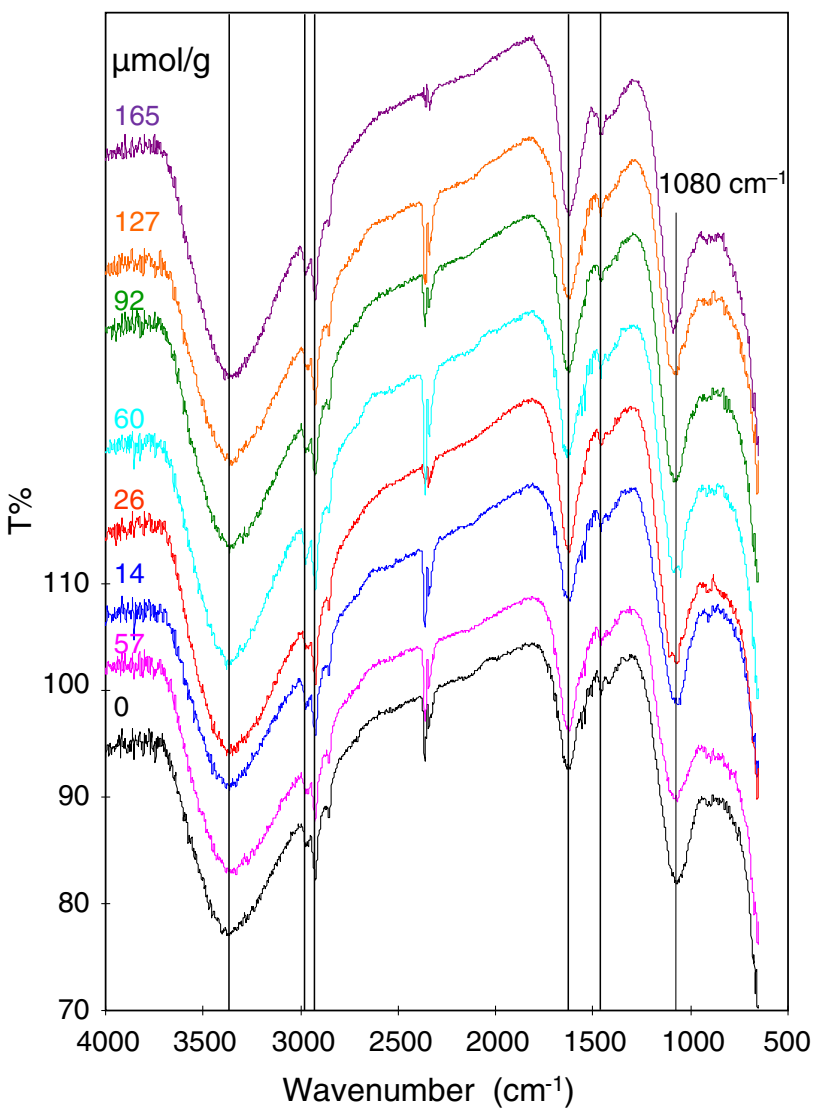

Fig. 10 FTIR spectra of birnessite after adsorbed with different amounts of TC and then desorbed with $50 \mathrm{mM}$ of $\mathrm{AlCl}_{3}$

$1.43 \mathrm{mmol}_{\mathrm{c}} / \mathrm{g}$. In comparison, adsorption of $\mathrm{Pb}$ on birnessite could be as high as $2.3 \mathrm{mmol} / \mathrm{g}$ (Wang et al. 2012). Adsorption of $\mathrm{Ni}$ on a birnessite was attributed to cation exchange with a capacity at $0.44 \mathrm{mmol} / \mathrm{g}$ at $\mathrm{pH} 7$ (Peña et al. 2010). With a CEC of $1.43 \mathrm{mmol}_{\mathrm{c}} / \mathrm{g}$, the charge density would be about $16 \AA^{2}$. Again the limiting factor for TC adsorption on birnessite would still be the surface area rather than the charge density, similar to CIP adsorption on birnessite (Jiang et al. 2013). A decrease in Mn average oxidation states would decrease vacant sites at interlayers of birnessites, resulting in decreased sorption capacity for heavy metals, despite the fact that the specific surface area increased almost linearly (Wang et al. 2012).

The ICP-OES analysis of Mn concentration was in the range of $0.5-2.8 \mathrm{mg} / \mathrm{L}$ at high $\mathrm{CIP}$ input, equivalent to $\mathrm{Mn}^{2+}$ generation up to $8 \mu \mathrm{eq} / \mathrm{g}$ (Jiang et al. 2013), compared to $0.15 \mathrm{mmol} / \mathrm{g}$ for TC removal in this study. If the production of $\mathrm{Mn}^{2+}$ was used as the degradation of TC by birnessite, the amount of $\mathrm{Mn}^{2+}$ produced accounted for only $5-6 \%$ of TC removal from water. The $\mathrm{Mn}^{2+}$ concentration after $4 \mathrm{~h}$ in equilibrium with $\mathrm{TC}$ at an initial concentration of $25 \mu \mathrm{M}$ was $150 \mu \mathrm{M}$, and the TC concentration dropped from 25 to $5 \mu \mathrm{M}$ in a previous study 


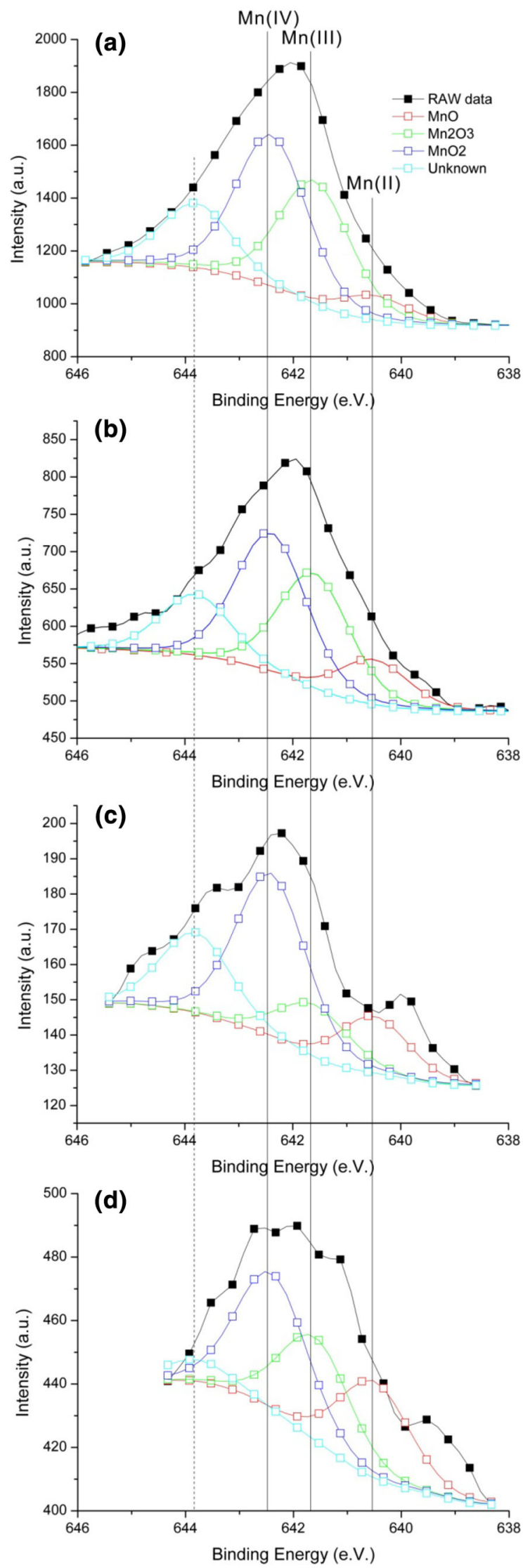

4Fig. 11 XPS spectra of raw birnessite (a), birnessite after 0.5-h (b) and 24-h (c) equilibration with TC and after desorption by $50 \mathrm{mM}$ of $\mathrm{AlCl}_{3}(\mathbf{d})$

(Chen and Huang 2011). Similarly, for oxytetracycline degradation by $\mathrm{MnO}_{2}$, accompanying $23 \mu \mathrm{M}$ of oxytetracycline degradation, $14 \mu \mathrm{M} \mathrm{Mn}{ }^{2+}$ was generated within only 2 min of contact (Rubert and Pedersen 2006). In comparison, the concentration ratio of $\mathrm{Mn}^{2+} / \mathrm{TC}$ after $24-\mathrm{h}$ equilibrium in this study was $2.8 \mathrm{mg} / \mathrm{L}$ against a TC concentration decrease of $800 \mathrm{mg} / \mathrm{L}$. Thus, this minute amount of increase in $\mathrm{Mn}^{2+}$ concentration in solution indicated that the degradation reaction between TC and birnessite might be trivial. Furthermore, the relative content of $\mathrm{Mn}(\mathrm{VI})$ did not change much among the raw birnessite, birnessite in contact with $2.25 \mathrm{mmol} / \mathrm{L}$ TC for 0.5 and $24 \mathrm{~h}$, and birnessite after TC desorption by $\mathrm{AlCl}_{3}$ (Fig. 11). Thus, the majority of TC removal in the presence of birnessite was still attributed to adsorption and intercalation, rather than degradation.

\section{Conclusion}

Antibiotic TC could be adsorptively removed using birnessite as the sorbent, and the mechanism of TC removal by birnessite was via cation exchange at lower adsorption levels as confirmed by the free energy of sorption and by the stoichiometric desorption of exchangeable cations. Both external and internal surface areas were available for TC uptake by birnessite. The adsorbed TC was primarily in cationic and zwitterionic forms. A monolayer of TC with a horizontal orientation would be the preferred configuration in the interlayer of birnessite. The adsorbed TC could be readily desorbed using high concentrations of $\mathrm{AlCl}_{3}$ solution, confirming that the removal of TC from solution was predominantly by adsorption instead of degradation.

Acknowledgments We are grateful to P.-S. Lee, A.-L. Huang, and C.-Y. Lin for their help with XRD and ICP-OES analyses, and K.-C. Huang for field sampling. This work was funded by grant NSC1012116-M-006-002 to Jiang from National Science Council and a grant to $\mathrm{Li}$ from the Headquarters of University Advancement at the National Cheng Kung University, which is sponsored by the Ministry of Education, Taiwan, ROC.

\section{References}

Al-Attar L, Dyer A (2007) Ion exchange in birnessite. Land Contam Reclam 15:427-436

Ammundsen B, Wortham E, Jones DJ, Rozière J (1998) Intercalation reactions of layered manganese(III, IV) oxides. Mol Cryst Liq Cryst 311:327-332 
Bound JP, Voulvoulis N (2004) Pharmaceuticals in the aquatic environment-a comparison of risk assessment strategies. Chemosphere 56:1143-1155

Chang PH, Jean JS, Jiang WT, Li Z (2009a) Mechanism of tetracycline sorption on rectorite. Colloid Surf A-Physicochem Eng Asp 339:94-99

Chang PH, Li Z, Yu TL, Munkhbayer S, Kuo TH, Hung YC, Jean JS, Lin KH (2009b) Sorptive removal of tetracycline from water by palygorskite. J Hazard Mater 165:48-155

Chang PH, Li Z, Jean JS, Jiang WT, Wang CJ, Lin KH (2012) Adsorption of tetracycline on 2:1 layered non-swelling clay mineral illite. Appl Clay Sci 67-68:158-163

Chen WR, Huang CH (2011) Transformation kinetics and pathways of tetracycline antibiotics with manganese oxide. Environ Pollut 159:1092-1100

Chen WR, Ding Y, Johnston CT, Teppen BJ, Boyd SA, Li H (2010) Reaction of lincosamide antibiotics with manganese oxide in aqueous solution. Environ Sci Technol 44:4486-4492

Chen G, Zhao L, Dong YH (2011) Oxidative degradation kinetics and products of chlortetracycline by manganese dioxide. J Hazard Mater 193:128-138

Collaizzi JL, Klink PR (1969) pH partition behavior of tetracyclines. J Pharm Sci 58:1184-1189

Drits VA, Lanson B, Gaillot AC (2007) Birnessite polytype systematics and identification by powder X-ray diffraction. Am Miner 92:771-788

Duarte HA, Carvalho S, Paniago EB, Simas AM (1999) Importance of tautomers in the chemical behavior of tetracyclines. J Pharm Sci 88:111-120

Fendorf SE, Sparks DL, Fendorf M (1994) Mechanism of aluminum sorption on birnessite: Influences on chromium (III) oxidation. In: Proceedings of the 15th World Congr Soil Sci 3a, Intl Soc Soil Sci Publ pp 129-144

Figueroa RA, Mackay AA (2005) Sorption of oxytetracycline to iron oxides and iron oxide-rich soils. Environ Sci Technol 39:6664-6671

Figueroa RA, Leonard A, Mackay AA (2004) Modeling tetracycline antibiotic sorption to clays. Environ Sci Technol 38:476-483

Figueroa RA, Vasudevan D, MacKay AA (2010) Trends in soil sorption coefficients within common antimicrobial families. Chemosphere 79:786-793

Gambinossi F, Mecheri B, Nocentini M, Puggelli M, Caminati G (2004) Effect of the phospholipid head group in antibioticphospholipid association at water-air interface. Biophys Chem 110:101-117

Gao J, Hedman C, Liu C, Guo T, Pedersen JA (2012) Transformation of sulfamethazine by manganese oxide in aqueous solution. Environ Sci Technol 46:2642-2651

Golden DC, Chen CC, Dixon JB (1986) Ion exchange, thermal transformations and oxidising properties of birnessite. Clays Clay Miner 34:511-520

Grangeon S, Lanson B, Miyata N, Tani Y, Manceau A (2010) Structure of nanocrystalline phyllomanganates produced by freshwater fungi. Am Miner 95:1608-1616

Gu C, Karthikeyan KG (2005) Interaction of tetracycline with aluminum and iron hydrous oxides. Environ Sci Technol 39:2660-2667

Gu C, Karthikeyan KG (2008) Sorption of the antibiotics tetracycline to humic-mineral complexes. J Environ Qual 37:704-711

Gu C, Karthikeyan KG, Sibley SD, Pedersen JA (2007) Complexation of the antibiotic tetracycline with humic acid. Chemosphere 66:1494-1501

Jiang WT, Chang PH, Wang YS, Tsai Y, Jean JS, Li Z, Krukowski K (2013) Removal of ciprofloxacin from water by birnessite. J Hazard Mater 250-251:362-369
Jokic A, Frenkel AI, Huang PM (2001) Effect of light on birnessite catalysis of the Maillard reaction and its implication in humification. Can J Soil Sci 81:277-283

Kulshrestha P, Giese RF Jr, Aga DS (2004) Investigating the molecular interactions of oxytetracycline in clay and organic matter: insights on factors affecting its mobility in soil. Environ Sci Technol 38:4097-4105

Li Z, Chang PH, Jean JS, Jiang WT (2010a) Interaction between tetracycline and smectite in aqueous solution. J Colloid Interface Sci 341:311-319

Li Z, Schulz L, Ackley C, Fenske N (2010b) Mechanism of tetracycline adsorption on kaolinite with $\mathrm{pH}$-dependent surface charges. J Colloid Interface Sci 351:254-260

Liu Z, Ooi K, Kanoh H, Tang W, Tomida T (2000) Swelling and delamination behaviors of birnessite-type manganese oxide by intercalation of tetraalkylammonium ions. Langmuir $16: 4154-4164$

Liu C, Zhang L, Li F, Wang Y, Gao Y, Li X, Cao X, Feng C, Dong J, Sun L (2009) Dependence of sulfadiazine oxidative degradation on physicochemical properties of manganese dioxides. Ind Eng Chem Res 48:10408-10413

Miller GH, Smith HL, Rock WL, Hedberg S (1977) Antibacterial structure-activity relationships obtained with resistant microorganisms. I: inhibition of R-factor resistant Escherichia coli by tetracyclines. J Pharm Sci 66:88-92

Mohan D, Pittman CU Jr (2007) Arsenic removal from water/ wastewater using adsorbents-a critical review. J Hazard Mater 142:1-53

Othersen OG, Beierlein F, Lanig H, Clark T (2003) Conformations and tautomers of tetracycline. J Phys Chem B 107:13743-13749

Peña J, Kwon KD, Refson K, Bargar JR, Sposito G (2010) Mechanisms of nickel sorption by a bacteriogenic birnessite. Geochim Cosmochim Acta 74:3076-3089

Pils JRV, Laird DA (2007) Sorption of tetracycline and chlortetracycline on K- and Ca-saturated soil clays, humic substances, and clay-humic complexes. Environ Sci Technol 41:1928-1933

Post JE, Veblen DR (1990) Crystal structure determinations of synthetic sodium, magnesium, and potassium birnessite using TEM and the Rietveld method. Am Miner 75:477-489

Renuka R, Ramamurthy S (2000) An investigation on layered birnessite type manganese oxides for battery applications. J Power Sources 87:144-152

Rubert KF, Pedersen JA (2006) Kinetics of oxytetracycline reaction with a hydrous manganese oxide. Environ Sci Technol 40:7216-7220

Sarmah AK, Meyer MT, Boxall ABA (2006) A global perspective on the use, sales, exposure pathways, occurrence, fate and effects of veterinary antibiotics (VAs) in the environment. Chemosphere 65:725-759

Turku I, Sainio T, Paatero E (2007) Thermodynamics of tetracycline adsorption on silica. Environ Chem Lett 5:225-228

Wang Y, Feng X, Villalobos M, Tan W, Liu F (2012) Sorption behavior of heavy metals on birnessite: relationship with its Mn average oxidation state and implications for types of sorption sites. Chem Geol 292-293:25-34

Wessels JM, Ford WE, Szymczak W, Schneider S (1998) The complexation of tetracycline and anhydrotetracycline with $\mathrm{Mg}^{2+}$ and $\mathrm{Ca}^{2+}$ : a spectroscopic study. J Phys Chem B 102:9323-9331

White WB, Vito C, Scheetz BE (2009) The mineralogy and trace element chemistry of black manganese oxide deposits from caves. J Cave Karst Stud 71:136-143

Zhang H, Huang CH (2005) Oxidative transformation of fluoroquinolone antibacterial agents and structurally related amines by manganese oxide. Environ Sci Technol 39:4474-4483 